\title{
Degradabilidade ruminal In Situ dos componentes nutritivos de alguns suplementos concentrados usados na alimentação de bovinos ${ }^{1}$
}

\section{Ruminal degradability In Situ of nutritive components of some concentrates used in bovine feeding}

\author{
Ana Paula de Souza Fortaleza ${ }^{2 *}$; Leandro das Dores Ferreira da Silva ${ }^{3}$; \\ Edson Luis de Azambuja Ribeiro'; Rondineli Pavezzi Barbero ${ }^{4}$; \\ Fernando Luiz Massaro Júnior ${ }^{4}$; Angelita Xavier dos Santos ${ }^{4}$; \\ Valdecir de Souza Castro ${ }^{5}$; Filipe Alexandre Boscaro de Castro ${ }^{5}$
}

\section{Resumo}

As degradabilidades in situ da matéria seca (MS), matéria orgânica (MO), proteína bruta (PB), fibra em detergente ácido (FDA) e da fibra em detergente neutro (FDN) do caroço de algodão integral (CAI), farelo de soja (FS), grão de girassol (GG), torta de nabo forrageiro (TN) e do milho triturado (MT) foram determinadas com a incubação de sacos de náilon no rúmen de cinco bovinos $1 / 2$ sangue Simental-Zebu. As degradabilidades efetivas (DE) da matéria seca (MS) e da proteína bruta (PB) a taxa de passagem de $5 \% / \mathrm{h}$, foram, respectivamente, 40,93 e $48,95 \%$ para o caroço de algodão integral; 67,35 e 53,20\% para o farelo de soja; 63,38 e 72,50\% para o grão de girassol; 66,59 e 57,82 para torta de nabo forrageiro e 63,65 e 54,18\% para o milho triturado. Por meio das taxas de fermentação dos diferentes componentes nutritivos determinadas neste experimento, pode-se concluir que a torta de nabo forrageiro tem potencial para substituir o farelo de soja como fonte protéica na alimentação de ruminantes; o grão de girassol apresenta elevada fração solúvel da proteína bruta e o teor de extrato etéreo presente no caroço de algodão pode afetar negativamente a degradação da matéria seca e da matéria orgânica deste alimento, principalmente quando este é fornecido triturado aos animais.

Palavras-chave: Caroço de algodão, co-produtos, farelo de soja, grão de girassol, matéria orgânica, matéria seca, proteína bruta, taxa de passagem, torta de nabo forrageiro

\footnotetext{
Abstract

Degradability "in situ" of dry matter (DM), organic matter (OM), crude protein (CP), neutral detergent fiber (NDF) and acid detergent fiber (ADF) of whole cotton seed (WCS), soybean meal (SM), sunflower seed (SS), turnip cake (TC) and ground corn (GC) were determined with incubation of nylon bags in the rumen of five steers $1 / 2$ Simmental-Zebu. The effective degradability (ED) of dry matter and crude protein with $5 \% / \mathrm{h}$ of passage rate were respectively 40,93 and $48,95 \%$ for cotton seed; 67,35 and $53,20 \%$ for soybean meal; 63,38 and $72,50 \%$ for sunflower seed; 66,59 and $57,82 \%$ for turnip cake and 3,65 e $54,18 \%$ for ground corn. Through the fermentation rates of the different nutritious components determined on this experiment it was concluded that turnip cake has a potential to substitute soybean

Parte da dissertação do primeiro autor.

2 Zootecnista, mestranda do Programa de Pós-Graduação em Ciência Animal da Universidade Estadual de Londrina - UEL, bolsista do CNPq. E-mail: anapaula_fortaleza@yahoo.com.br

3 Professor Doutor do Departamento de Zootecnia da Universidade Estadual de Londrina - UEL. E-mail: leandro@uel.br

4 Zootecnista, graduado pela Universidade Estadual de Londrina - UEL.

5 Mestrandos do Programa de Pós Graduação em Ciência Animal da Universidade Estadual de Londrina.

* Autor para correspondência
} 
meal as a protein source in ruminant feeding; sunflower seed presents a high soluble fraction of crude protein and the cotton seed ether extract may affect negatively the degradation of dry matter and organic matter of this feed, specially when provided ground to the animals.

Key words: Co-products, cotton seed, crude protein, dry matter, organic matter, passage rate, soybean meal, sunflower seed, turnip cake

\section{Introdução}

O custo com alimentação representa cerca de $80 \%$ dos custos totais em sistemas de produção de bovinos de corte. Conseqüentemente, a formulação de dietas, ou seja, o fornecimento de nutrientes a partir dos alimentos disponíveis, é uma das mais importantes etapas de trabalho na produção de bovinos confinados (LANNA; TEDESCHI; BELTRAME FILHO, 1999).

Para alcançar altos níveis de produção é necessário fornecer aos animais ruminantes elevados níveis de concentrado, isto porque, os volumosos não apresentam níveis suficientes dos nutrientes necessários para maximinizar a produção, como energia, proteína, minerais e algumas vitaminas. De acordo com Preston (1998), a utilização de dietas de alto concentrado proporciona rápido ganho de peso e elevada eficiência alimentar, reduzindo o tempo para terminação e abate, além de proporcionar maior uniformidade do produto final.

As exigências protéicas dos animais ruminantes são atendidas pelos aminoácidos absorvidos no intestino delgado, provenientes, principalmente, da proteína microbiana e da proteína dietética não degradada no rúmen. O National Research Council - NRC (1996) e o Agricultural and Food Research Council - AFRC (1993) recomendam exigências protéicas em função da proteína metabolizável, que é definida como sendo a proteína verdadeira digerida no abomaso e os aminoácidos resultantes dessa digestão que são absorvidos pelo intestino. A estimativa da ingestão de proteína bruta necessária e calculada como sendo a quantidade proteína degradável no rúmen necessária ao crescimento microbiano mais a proteína não degradada no rúmen necessária para complementar o requerimento de proteína metabolizável para mantença e ganho que não foi atingido pela proteína de origem microbiana.
Por muito tempo acreditou-se que a degradação da proteína e do amido seria mais vantajosa se ocorresse no intestino delgado e não no rúmen. Isto porque supunha-se que evitando as perdas no processo fermentativo, maiores quantidades de energia e proteína seriam economizadas, resultando em melhoras no desempenho animal. Atualmente diversos trabalhos têm demonstrado vantagem das fontes ricas em proteína degradável no rúmen no desempenho de novilhos de corte em animais em crescimento (GABARRA, 2001; SOUZA et al., 2002), principalmente quando os animais recebiam dietas com alta proporção de concentrado, ricas em amido e/ou açúcares solúveis (ZINN; SHEN, 1998).

Além de fontes de nitrogênio, os microrganismos ruminais requerem também energia para seu crescimento. De acordo com Van Soest (1994) esses são os principais fatores que afetam o crescimento e a eficiência microbiana. Hoover e Stokes (1991) observaram maior síntese de proteína microbiana quando vacas de leite foram alimentadas com dietas contendo altas proporções de carboidratos não estruturais e proteína degradável no rúmen (38 e $13,2 \%$, respectivamente) em comparação com dietas contendo 24 e $9 \%$ de carboidratos não estruturais e proteína degradável no rúmen, respectivamente. Essa otimização da produção de proteína microbiana ocorre devido à sincronização entre a degradação ruminal da proteína e carboidratos da dieta.

Quando a degradação da proteína ocorre mais rapidamente em relação a fonte de energia, há um desacoplamento da fermentação, aumentando a concentração de amônia ruminal, que é absorvida pela parede do rúmen e convertida em uréia no fígado (NORLAN, 1975). Essa uréia pode ser reciclada via saliva ou parede do rúmen, no entanto, a maior proporção é excretada na urina. Quando a energia é 
degradada mais rapidamente em relação a proteína, tanto o crescimento microbiano, como a eficiência digestiva decrescem. Isto é caracterizado pela fermentação incompleta, onde os microrganismos, deficientes em $\mathrm{N}$, desviam ATP para o acúmulo de carboidrato e não para a síntese de proteína microbiana (NOCEK; RUSSEL, 1988).

Nos últimos anos agrícolas, a produção dos alimentos energéticos e protéicos, componentes das rações para produção de carne bovina, tem apresentado grande oscilação na sua oferta em virtude de variações no rendimento de grãos. Este cenário, associado à desvalorização da moeda nacional, contribuiu, de acordo com Neumann et al. (2002), para o aumento dos custos de produção dos insumos e, com a não valorização adequada do produto final, a alimentação de bovinos de corte tornou-se um investimento oneroso ao produtor.

Neste sentido há um crescente interesse sobre o aproveitamento de co-produtos originados na produção agrícola e agroindústria na alimentação animal com o objetivo de se fornecer alimentos alternativos e economicamente viáveis, sem concorrer com a alimentação humana.

Em virtude da diminuição das reservas petrolíferas no mundo e iminentes crises do petróleo, o alto preço deste combustível tem impulsionado a procura por fontes alternativas de energia, dentre elas, o biodísel tem se destacado por ser uma fonte de energia renovável e de menor custo de obtenção em relação, por exemplo, a energia solar ou eólica (PENIDO, 2007). O nabo forrageiro, assim como o girassol e a mamona, pode ser utilizado para extração de óleo que após um processo de transesterificação origina o biodísel.

A torta de nabo forrageiro, co-produto gerado deste procedimento, bem como outras tortas e farelos resultantes da prensagem para produção de biodísel, apresenta potencial de utilização na alimentação de ruminantes, principalmente em virtude de seu alto teor de proteína, podendo reduzir os custos de produção. No entanto, para que tragam benefícios nos índices produtivos, torna-se necessária a caracterização destes.

A técnica de degradabilidade in situ, avalia os parâmetros cinéticos da degradação ruminal dos alimentos por meio do desaparecimento da massa de amostra incubada e, de acordo com vários pesquisadores (JOHNSON, 1966; MEHREZ; ORSKOV, 1977; ORSKOV; HOVELL; MOULD, 1980), é um método preciso, simples e rápido para determinar o valor nutritivo de um alimento. De acordo com Van Soest (1994), embora o alimento não esteja sujeito a todos os eventos digestivos, como mastigação, ruminação e passagem, não há melhor forma de simulação do ambiente ruminal para um dado regime de alimentação do que a técnica in situ, isto porque esta técnica permite o contato íntimo do alimento teste com o ambiente ruminal.

Nos últimos anos, tem se verificado uma padronização da metodologia nos ensaios de degradação, principalmente no que se refere aos tempos de incubação, material de confecção dos sacos, bem como a metodologia para a lavagem dos mesmos, tornando os resultados obtidos em diferentes instituições de pesquisa passíveis de comparações.

O presente trabalho teve como objetivo determinar as degradabilidades in situ da matéria seca (MS), matéria orgânica (MO), proteína bruta (PB), fibra em detergente neutro (FDN) e fibra em detergente ácido (FDA), em bovinos, do caroço de algodão integral, farelo de soja, grão de girassol, torta de nabo forrageiro e milho triturado, levando em consideração as taxas de passagem de 3; 5 e $8 \% / \mathrm{h}$ preconizadas pelo AFRC (1993).

\section{Material e Métodos}

Este experimento foi realizado nas instalações da Unidade Experimental de Bovinos de Corte (UNEB) da Fazenda Escola e as análises laboratoriais foram realizadas no Laboratório de Nutrição Animal do Departamento de Zootecnia (DZO), da Universidade Estadual de Londrina (UEL). 
Foram utilizados cinco bovinos $1 / 2$ sangue Simental-Zebu, com aproximadamente 24 meses de idade, pesando em média $480 \mathrm{~kg}$, castrados e providos de fístulas permanentes no rúmen, distribuídos em um delineamento inteiramente casualizado em cinco tratamentos (alimentos) em um esquema de parcelas subdivididas, representadas pelos tempos de incubação.

O volumoso utilizado na formulação da ração experimental foi a silagem de cana-de-açúcar. A ração completa foi composta por uma relação volumoso:concentrado de 56:44, balanceada com 14\% PB, de forma a atender as exigências nutricionais conforme as recomendações do NRC (1996). O farelo de soja (FS), a torta de nabo forrageiro (TN), o grão de girassol (GG) e o caroço de algodão integral (CAI) foram utilizados como fontes suplementares de proteína, enquanto o milho triturado (MT) foi utilizado para o ajuste da exigência energética. $\mathrm{O}$ sal mineralizado (SM) foi misturado na ração concentrada a $0,37 \%$, base na matéria seca (MS), para atender as exigências dos animais em macro e micro minerais.

A composição química e bromatológica dos ingredientes usados podem ser visualizadas, Tabelas 1.

O fornecimento da ração completa aos animais foi feito de forma que as sobras nos cochos em um período de 24 horas fossem de 5 a $10 \%$ da matéria seca fornecida em dois arraçoamentos diários, as 8 e às 18 horas.

Tabela 1. Composição química e bromatológica dos ingredientes usados na ração (\%MS).

\begin{tabular}{lcccccc}
\hline Ingredientes & $\begin{array}{c}\text { Silagem de } \\
\text { Cana }\end{array}$ & $\begin{array}{c}\text { Caroço de } \\
\text { Algodão }\end{array}$ & $\begin{array}{c}\text { Farelo de } \\
\text { Soja }\end{array}$ & $\begin{array}{c}\text { Grão de } \\
\text { Girassol }\end{array}$ & $\begin{array}{c}\text { Torta de } \\
\text { Nabo }\end{array}$ & $\begin{array}{c}\text { Milho } \\
\text { Triturado }\end{array}$ \\
MS & 20,37 & 92,61 & 88,79 & 92,65 & 94,87 & 88,88 \\
MO & 98,79 & 96,33 & 93,94 & 94,96 & 94,94 & 98,67 \\
EE & 1,34 & 15,42 & 2,90 & 32,65 & 14,26 & 3,09 \\
PB & 4,50 & 21,66 & 52,15 & 15,99 & 43,31 & 10,50 \\
FDN & 81,97 & 63,23 & 9,40 & 38,73 & 15,43 & 9,38 \\
FDA & 51,69 & 41,78 & 7,51 & 32,32 & 14,23 & 6,53 \\
Hemic. & 30,28 & 21,45 & 1,89 & 6,42 & 1,20 & 2,86 \\
LDA $^{1}$ & 7,96 & 8,40 & 8,40 & 38,20 & 2,56 & 0,45 \\
CHT & 89,96 & 59,24 & 38,20 & 46,32 & 37,37 & 85,08 \\
\hline
\end{tabular}

1- LDA: Lignina obtida por meio de digestão ácida $\left(\mathrm{H}_{2} \mathrm{SO}_{4}\right.$ a $\left.72 \%\right)$.

As degradabilidades da MS, MO, PB, FDN e FDA, do caroço de algodão(CAI), farelo de soja(FS), grão de girassol (GG), torta de nabo forrageiro (TN) e do milho triturado (MT), foram determinadas pela técnica in situ, utilizando-se sacos confeccionados em náilon $100 \%$ poliamida, não resinado, medindo $14,00 \mathrm{~cm} \times 7,00 \mathrm{~cm}$, com poros de 50 micrômetros, selados por infusão com resistência elétrica. Estes foram identificados, pesados e receberam, em média, sete gramas de matéria seca de cada um dos alimentos anteriormente citados, triturados previamente em moinho dotado de peneira com crivos de $2 \mathrm{~mm}$ de diâmetro.

Após um período de 15 dias de adaptação á dieta e ao manejo experimental, os sacos de náilon, em número de 10 repetições para os tempos $3 ; 6 ; 12$; 24; 48 e 72 horas de incubação foram amarrados aos elos de uma corrente com $50 \mathrm{~cm}$ de comprimento, pesando aproximadamente $500 \mathrm{~g}$, presa por um cordão de seda à tampa da cânula. Devido ao grande número de sacos de náilon, 300 no total (cinco alimentos, 10 repetições e seis tempos), foram 
incubados 50 sacos (cinco alimentos e 10 repetições) em cada tempo, retirados e posteriormente incubados os sacos referentes ao próximo tempo.

Os sacos de náilon, ainda presos nas correntes, foram lavados em água fria para retirado do excesso de conteúdo ruminal e, em seguida, mergulhados por um período de 30 minutos em água com gelo para interromper a atividade dos microorganismos. Em seguida foram retirados das correntes e lavados em água corrente até que a água ficasse clara. Após estes procedimentos, os sacos foram pendurados em um suporte de ferro para secar em estufa com ventilação de ar forçada, com temperatura de $55^{\circ} \mathrm{C}$ $\pm 5^{\circ} \mathrm{C}$, durante 72 horas.

Foram utilizados quatro sacos de náilon contendo amostras de cada alimento estudado que não foram incubados no rúmen, mas passaram pelos mesmos procedimentos daqueles com resíduos não digeridos no rúmen, para quantificação das frações solúveis dos diferentes componentes nutritivos dos alimentos estudados.

A fração solúvel (A) de todos os componentes nutritivos avaliados foi obtida pela diferença entre as quantidades contidas inicialmente na amostra dos alimentos e aquelas determinadas nos resíduos após lavados, secos e triturados.

Os sacos com as amostras residuais, não digeridas e insolúveis, após secos, foram pesados e as amostras de cada alimento incubado e dos resíduos nos sacos de náilon foram triturados a um milímetro para determinar a MS, MM, PB, FDN e FDA.

A fração indegradável (C) foi considerada como sendo o resíduo encontrado no saco de náilon após 72 horas de permanência do rúmen. Para a avaliação da degradação potencial da MS, MO, PB, FDN e FDA foi utilizado o modelo proposto por Orskov e McDonald (1979), onde $\mathrm{p}=\mathrm{a}+\mathrm{b}\left(1-\mathrm{e}^{\mathrm{kt}}\right)$, em que em que; $\mathrm{p}=$ degradação potencial do componente nutritivo em porcentagem, $a=$ fração solúvel em porcentagem, $b=$ fração insolúvel potencialmente degradável em porcentagem, $\mathrm{a}+\mathrm{b}=$ degradação potencial do componente nutritivo, $\mathrm{k}=$ taxa de digestão por ação fermentativa em porcentagem por hora e $\mathrm{t}=$ tempo de incubação em horas.

Para estimar a degradabilidade efetiva foi usada a expressão $\mathrm{P}=\mathrm{a}+\mathrm{b} * \mathrm{k}(\mathrm{kd}+\mathrm{kp})-1$ sendo $\mathrm{P}=$ degradabilidade efetiva em porcentagem, $\mathrm{kd}$ = taxa específica de digestão, $\mathrm{kp}=$ ritmo de fluxo das frações nutritivas por hora, sendo que foram utilizados os valores de $\mathrm{kp}$ de $3 \% / \mathrm{h}$ e 5 e $8 \%$ /hora sugerido pelo AFRC, (1993), e a, b e k as mesmas constantes da equação, anteriormente citada.

Os dados obtidos foram submetidos à análise de variância, e as diferenças entre médias comparadas pelo Teste Tukey por meio do procedimento GLM do Statistical Analysis System - SAS (2003) a 5\% de probabilidade.

\section{Resultados e Discussão}

A composição bromatológica dos alimentos (Tabela 1) foi semelhante à encontrada na literatura (BRISOLA et al., 1999; VILLELA et al., 1996; BERAN et al., 2005). O teor de FDN encontrado neste estudo para o caroço de algodão integral $(63,23 \%)$ foi superior a $48,10 \%$ relatado por Villela et al. (1996). Esta diferença se deve, provavelmente ao fato de o caroço de algodão utilizado pelo autor ser desprovido de línter, material que envolve o caroço de algodão composto basicamente de material fibroso.

A torta de nabo forrageiro apresentou elevado teor de PB e EE, 43,31\% e 14,26\%, respectivamente, podendo ser considerada, assim como o caroço de algodão integral e o grão de girassol, um alimento protéico de elevado valor energético. No entanto o elevado teor de EE deste alimento pode dificultar a armazenagem do mesmo por longos períodos.

Para formulação de rações balanceadas para animais ruminantes apenas a composição bromatológica de um alimento não é suficiente. É necessário caracterizar o comportamento deste alimento no ambiente ruminal, para que desta forma 
seja possível sincronizar a digestão ruminal de proteínas e carboidratos, com o objetivo de obter o máximo desempenho dos microrganismos ruminais, a redução de perdas nitrogenadas, a redução da emissão de metano e a estimativa do escape ruminal de nutrientes (SNIFFEN et al., 1992).

O desaparecimento da matéria seca (MS), matéria orgânica $(\mathrm{MO})$, proteína bruta $(\mathrm{PB})$, fibra em detergente neutro (FDN) e fibra em detergente ácido (FDA) dos alimentos incubados, podem ser visualizados na Tabela 2.

De acordo com Mir et al. (1984), o teor de óleo de um alimento incubado pode obstruir os poros dos sacos de náilon e diminuir a degradação. Isto porque, durante o processo de moagem o envoltório rígido da amêndoa é parcialmente pulverizado pelo moinho e mistura-se a gordura do alimento, dificultando a passagem de partículas pela malha da peneira (MOREIRA et al., 2003). Este fato pode ser observado quando se analisa a degradação da MS do caroço de algodão. Este alimento apresentou, em todos os tempos de incubação, menor taxa de degradação da MS, refletindo também em menor degradação da MO e da PB.

Observa-se que, apesar da menor degradação da matéria seca, o padrão da curva de degradação do caroço de algodão integral foi semelhante aos demais alimentos, com exceção do grão de girassol. Este alimento apresentou elevada solubilidade da matéria seca $(53,65 \%)$ e taxa de degradação praticamente constante, diferindo da curva de degradação dos demais alimentos.

A análise bromatológica dos alimentos revelou que o teor de extrato etéreo presente no caroço de algodão $(15,42 \%)$ e na torta de nabo forrageiro $(14,26 \%)$ é semelhante, no entanto, durante as análises laboratoriais, foi observado um maior desprendimento de pigmentos para a torta de nabo, o que sugere que o caroço de algodão apresenta um maior teor de gordura. Durante a incubação pode ser observado também que os sacos de náilon que continham caroço de algodão integral, se apresentavam engordurados ao toque, o que não ocorria com a torta de nabo.

A torta de nabo forrageiro apresentou nos tempos 3; 12 e 24 horas taxa de desaparecimento da matéria seca semelhante ao farelo de soja, no entanto, nos tempos 48 e 72 horas a degradação do farelo de soja foi significativamente maior. A degradação de $98,32 \%$ da matéria seca do farelo de soja encontrada neste estudo foi semelhante às divulgadas por Beran et al. (2005) e Brisola et al. (1999) de 98,60 e $99,08 \%$, respectivamente.

No tempo 12 horas, todos os alimentos, com exceção do caroço de algodão integral, apresentaram taxa de desaparecimento da matéria seca semelhante.

A matéria orgânica apresenta grande relação com a energia disponível (AROEIRA; LOPES; DAYRELL, 1996), sendo assim, a degradabilidade da matéria orgânica pode ser considerada como a energia digerida no rúmen. É possível verificar que há uma grande semelhança entre as taxas de desaparecimento da matéria seca e da matéria orgânica, indicando que a degradabilidade da matéria seca pode ser utilizada para estimar a energia disponível no rúmen para o desenvolvimento dos microrganismos ruminais.

A torta de nabo apresenta, nos tempos iniciais, maior taxa de degradação da matéria orgânica em relação ao milho triturado, no entanto, a partir de 48 horas de incubação este comportamento se inverte e o milho triturado passa então, a apresentar maior degradação, característica de grãos de cereais, ricos em carboidratos, cuja principal função é disponibilizar energia para a microbiota ruminal e para o animal hospedeiro (ZEOULA; CALDAS NETO, 2001). 
Tabela 2. Degradabilidade aparente (\%) da matéria seca, matéria orgânica, proteína bruta, fibra em detergente neutro e da fibra em detergente ácido do caroço de algodão integral (CAI), farelo de soja (FS), grão de girassol (GG), torta de nabo forrageiro (TN) e milho triturado (MT), de acordo com o tempo de incubação.

\begin{tabular}{|c|c|c|c|c|c|c|c|}
\hline \multicolumn{8}{|c|}{ TEMPO (HORAS) } \\
\hline Alimentos & 0 & 3 & 6 & 12 & 24 & 48 & 72 \\
\hline \multicolumn{8}{|c|}{ MATÉRIA SECA } \\
\hline CAI & $24,39^{\mathrm{c}}$ & $24,24^{\mathrm{d}}$ & $26,94^{\mathrm{d}}$ & $45,54^{\mathrm{b}}$ & $51,21^{\mathrm{c}}$ & $54,17^{\mathrm{d}}$ & $60,43^{\mathrm{d}}$ \\
\hline FS & $31,72^{\mathrm{b}}$ & $40,15^{\mathrm{b}}$ & $49,31 b^{c}$ & $65,55^{\mathrm{a}}$ & $82,46^{\mathrm{a}}$ & $92,82^{\mathrm{a}}$ & $98,32^{\mathrm{a}}$ \\
\hline GG & $53,65^{\mathrm{a}}$ & $56,81^{\mathrm{a}}$ & $62,73^{\mathrm{a}}$ & $64,52^{\mathrm{a}}$ & $67,38^{\mathrm{b}}$ & $71,37^{\mathrm{c}}$ & $73,15^{\mathrm{c}}$ \\
\hline $\mathrm{TN}$ & $31,26^{\mathrm{b}}$ & $40,71^{\mathrm{b}}$ & $52,52^{\mathrm{b}}$ & $70,00^{\mathrm{a}}$ & $81,22^{\mathrm{a}}$ & $87,55^{\mathrm{b}}$ & $89,16^{\mathrm{b}}$ \\
\hline MT & $23,16^{\mathrm{c}}$ & $35,47^{\mathrm{c}}$ & $44,72^{\mathrm{c}}$ & $63,48^{\mathrm{a}}$ & $82,93^{\mathrm{a}}$ & $94,02^{\mathrm{a}}$ & $99,15^{\mathrm{a}}$ \\
\hline $\mathrm{CV}$ & 2,52 & 5,60 & 8,29 & 6,34 & 3,56 & 3,35 & 3,05 \\
\hline \multicolumn{8}{|c|}{ MATÉRIA ORGÂNICA } \\
\hline CAI & $27,00^{\mathrm{d}}$ & $34,24^{\mathrm{c}}$ & $39,13^{\mathrm{d}}$ & $41,66^{\mathrm{c}}$ & $49,84^{\mathrm{d}}$ & $53,13^{\mathrm{d}}$ & $59,37^{\mathrm{d}}$ \\
\hline FS & $33,32^{\mathrm{b}}$ & $44,63^{\mathrm{b}}$ & $60,06^{\mathrm{a}}$ & $79,45^{\mathrm{a}}$ & $89,21^{\mathrm{a}}$ & $94,95^{\mathrm{a}}$ & $99,08^{\mathrm{a}}$ \\
\hline GG & $52,72^{\mathrm{a}}$ & $56,42^{\mathrm{a}}$ & $61,63^{\mathrm{a}}$ & $62,98^{\mathrm{b}}$ & $66,13^{\mathrm{c}}$ & $70,42^{\mathrm{c}}$ & $72,40^{\mathrm{c}}$ \\
\hline $\mathrm{TN}$ & $31,23^{\mathrm{c}}$ & $43,04^{\mathrm{b}}$ & $53,41^{\mathrm{b}}$ & $69,32^{\mathrm{b}}$ & $78,82^{\mathrm{b}}$ & $87,74^{\mathrm{b}}$ & $89,11^{\mathrm{b}}$ \\
\hline MT & $22,24^{\mathrm{e}}$ & $35,97^{\mathrm{c}}$ & $45,59^{\mathrm{c}}$ & $65,67^{\mathrm{b}}$ & $84,44 a^{b}$ & $95,39^{\mathrm{a}}$ & $96,18^{\mathrm{a}}$ \\
\hline $\mathbf{C V}$ & 2,33 & 4,24 & 4,02 & 6,89 & 4,36 & 3,14 & 2,65 \\
\hline \multicolumn{8}{|c|}{ PROTEÍNA BRUTA } \\
\hline CAI & $25,48^{\mathrm{c}}$ & $34,60^{\mathrm{d}}$ & $40,46^{\mathrm{d}}$ & $69,00^{\mathrm{cb}}$ & $85,10^{\mathrm{c}}$ & $87,42^{\mathrm{c}}$ & $90,15^{\mathrm{d}}$ \\
\hline FS & $24,90^{\mathrm{c}}$ & $38,54^{\mathrm{c}}$ & $58,36^{\mathrm{b}}$ & $83,48^{\mathrm{a}}$ & $95,10^{\mathrm{a}}$ & $97,52^{\mathrm{a}}$ & $99,61^{\mathrm{a}}$ \\
\hline GG & $62,36^{\mathrm{a}}$ & $67,18^{\mathrm{a}}$ & $73,90^{\mathrm{a}}$ & $78,91^{\mathrm{a}}$ & $87,21^{\mathrm{c}}$ & $90,05^{\mathrm{c}}$ & $91,54^{\mathrm{c}}$ \\
\hline $\mathrm{TN}$ & $34,18^{b}$ & $46,02^{b}$ & $56,99^{\mathrm{b}}$ & $77,21^{\mathrm{ab}}$ & $91,08^{b}$ & $94,76^{\mathrm{b}}$ & $96,10^{\mathrm{b}}$ \\
\hline MT & $27,04^{\mathrm{c}}$ & $37,48^{\mathrm{c}}$ & $47,14^{\mathrm{c}}$ & $65,87^{\mathrm{c}}$ & $84,13^{\mathrm{c}}$ & $95,38^{\mathrm{b}}$ & $97,09^{b}$ \\
\hline $\mathbf{C V}$ & 5,04 & 2,73 & 5,71 & 5,89 & 1,8 & 1,14 & 0,73 \\
\hline \multicolumn{8}{|c|}{ FIBRA EM DETERGENTE NEUTRO } \\
\hline CAI & $16,14^{\mathrm{b}}$ & $25,87^{\mathrm{b}}$ & $31,77^{\mathrm{c}}$ & $38,08^{\mathrm{b}}$ & $43,21^{\mathrm{b}}$ & $47,55^{\mathrm{c}}$ & $61,15^{\mathrm{b}}$ \\
\hline FS & $16,06^{\mathrm{b}}$ & $18,03^{\mathrm{c}}$ & $21,03^{\mathrm{c}}$ & $39,04^{b}$ & $63,60^{\mathrm{a}}$ & $70,17^{\mathrm{b}}$ & $67,15^{\mathrm{e}}$ \\
\hline GG & $23,93^{\mathrm{a}}$ & $32,64^{\mathrm{a}}$ & $45,69^{\mathrm{a}}$ & $53,24^{\mathrm{a}}$ & $64,21^{\mathrm{a}}$ & $73,45^{\mathrm{a}}$ & $78,70^{\mathrm{a}}$ \\
\hline $\mathrm{TN}$ & $6,74^{\mathrm{c}}$ & $15,02^{\mathrm{d}}$ & $17,85^{\mathrm{d}}$ & $22,06^{\mathrm{c}}$ & $28,08^{\mathrm{c}}$ & $29,26^{\mathrm{d}}$ & $40,89^{d}$ \\
\hline MT & $8,04^{\mathrm{c}}$ & $10,48^{\mathrm{e}}$ & $15,48^{\mathrm{e}}$ & $22,31^{\mathrm{c}}$ & $26,43^{\mathrm{c}}$ & $46,83^{\mathrm{c}}$ & $50,04^{\mathrm{c}}$ \\
\hline $\mathbf{C V}$ & 2,90 & 3,34 & 2,36 & $3, \mathbf{5 0}$ & 3,63 & 4,14 & 2,70 \\
\hline \multicolumn{8}{|c|}{ FIBRA EM DETERGENTE ÁCIDO } \\
\hline CAI & $9,91^{\mathrm{c}}$ & $16,87^{\mathrm{d}}$ & $23,11^{\mathrm{d}}$ & $32,46^{\mathrm{d}}$ & $44,63^{\mathrm{c}}$ & $46,09^{\mathrm{c}}$ & $57,04^{\mathrm{d}}$ \\
\hline FS & $26,09^{\mathrm{a}}$ & $32,21^{\mathrm{b}}$ & $42,25^{\mathrm{b}}$ & $60,46^{\mathrm{b}}$ & $80,03^{\mathrm{a}}$ & $92,73^{\mathrm{a}}$ & $96,61^{\mathrm{a}}$ \\
\hline GG & $13,97^{\mathrm{b}}$ & $21,45^{\mathrm{c}}$ & $36,16^{\mathrm{c}}$ & $46,05^{\mathrm{c}}$ & $58,12^{\mathrm{b}}$ & $69,71^{\mathrm{b}}$ & $76,05^{\mathrm{c}}$ \\
\hline $\mathrm{TN}$ & $7,22^{\mathrm{d}}$ & $12,29^{\mathrm{e}}$ & $16,30^{\mathrm{e}}$ & $25,55^{\mathrm{e}}$ & $28,39^{\mathrm{d}}$ & $32,55^{\mathrm{d}}$ & $36,81^{\mathrm{e}}$ \\
\hline MT & $7,02^{\mathrm{d}}$ & $68,69^{\mathrm{a}}$ & $70,33^{\mathrm{a}}$ & $73,38^{\mathrm{a}}$ & $79,49^{\mathrm{a}}$ & $91,22^{\mathrm{a}}$ & $93,21^{b}$ \\
\hline $\mathrm{CV}$ & 3,79 & 2,20 & 2,63 & $\mathbf{3 , 8 9}$ & 2,37 & 1,65 & 1,38 \\
\hline
\end{tabular}

$\mathrm{a}, \mathrm{b}, \mathrm{c}, \mathrm{d}, \mathrm{e}-$ Médias acompanhadas de letras diferentes para o mesmo tempo, dentro de nutrientes, diferem $(\mathrm{P}<0,05)$ pelo teste Tukey. $\mathrm{CV}=$ coeficiente de variação

A curva de degradação da MO do grão de girassol, indica que este alimento possui uma alta solubilidade deste nutriente, disponibilizando, inicialmente grande quantidade de energia no interior do rúmen.
A utilização do grão de girassol triturado como fonte de energia para ruminantes, requer critério no manejo alimentar, isto porque com a trituração ou quebra do grão ocorre maior disponibilidade de óleo no rúmen. De acordo com Van Soest (1994), 
os ácidos graxos insaturados possuem ação tóxica sobre os microrganismos gram-positivos, como por exemplo, as bactérias fibrolíticas, podendo acarretar problemas relacionados ao decréscimo na degradação da fibra presente na dieta, com conseqüente diminuição na taxa de passagem e redução no consumo de matéria seca (PALMQUIST; JENKINS, 1980).

O caroço de algodão, outro alimento energético protéico, apresenta também elevado teor de ácidos graxos instaurados, com o ácido linoléico compreendendo $62 \%$ e o ácido oléico $15 \%$ do total (SMITH et al., 1981). Neste sentido a torta de nabo forrageiro pode ser utilizada para substituir, como fonte energética, o caroço de algodão ou o grão de girassol na alimentação de ruminantes por possuir menor quantidade de óleo e maior degradabilidade da MO (Tabela 2).

O milho triturado apresentou maior degradabilidade da $\mathrm{MO}$ em relação à torta de nabo forrageiro, 96,18 e 89,11\%, respectivamente. No entanto a utilização da torta de nabo forrageiro em substituição ao milho em rações destinadas a ruminantes pode ser vantajosa em virtude do elevado teor de proteína bruta da torta de nabo forrageiro $(43,31 \%)$.

As degradabilidades da PB do farelo de soja e da torta de nabo forrageiro foram semelhantes (Tabela 2). Nos tempos iniciais foi verificado maior taxa de degradação da proteína bruta da torta de nabo forrageiro em decorrência da maior fração solúvel deste alimento em relação ao farelo de soja, 34,18 e $24,90 \%$, respectivamente. Nos tempos 6 e 12 horas a taxa de desaparecimento foi semelhante e a partir de então o comportamento se inverte e o farelo de soja apresenta uma maior degradação deste componente nutritivo.

A proteína bruta do grão de girassol e da torta de nabo forrageiro apresentaram altas solubilidades, sendo, no entanto, após 12 horas menos degradadas em relação ao farelo de soja. O AFRC (1993) preconiza taxa de passagem de 3; 5 e $8 \%$ /hora para animais de baixo, médio e alto padrão de alimentação ou produtivo, respectivamente. Sendo assim, podese sugerir que o grão de girassol e a torta de nabo forrageiro poderão ser tão eficientes quanto o farelo de soja para aqueles animais com baixo e médio padrão produtivo, podendo, no entanto, ser superior ao farelo de soja na alimentação de animais de maior produção, desde que associados a volumosos com maior valor nutricional.

O grão de girassol apresentou proteína bruta com alta fração solúvel $(62,36 \%)$, resultado semelhante ao relatado por Beran et al. (2005) (69,08\%) e superiores ao divulgado por Bett et al. (2004) (44,2\%) para o grão de girassol quebrado. $\mathrm{O}$ grão de girassol utilizado neste estudo foi moído em moinho dotado de peneira com $2 \mathrm{~mm}$, o que explica, devido a maior área de contato para o ataque dos microrganismos, a superioridade da fração solúvel em relação ao valor divulgado por Bett et al. (2004)

Quando a proteína é rapidamente degradada no rúmen podem ser produzidas quantidades de amônia superiores àquelas necessárias para o crescimento dos microrganismos. Neste caso, o excesso de amônia pode ser absorvido através da parede do rúmen e metabolizado no fígado ou pode passar para os compartimentos digestivos posteriores (SILVA; LEÃO, 1979). No entanto para que esta proteína seja mais eficientemente utilizada pelos microrganismos ruminais, torna-se necessário, em quantidade e qualidade, ácidos graxos voláteis liberados por meio dos processos fermentativos no rúmen. Sendo assim, os resultados sobre a degradação da proteína bruta do grão de girassol sugerem que este componente nutritivo pode ser mais eficientemente utilizado com outros alimentos que possuam taxas mais rápidas de fermentação dos componentes fibrosos, visando uma maior quantidade de ácidos graxos voláteis e sincronismo entre nitrogênio e carbono liberados no rúmen para a síntese microbiana.

O comportamento da degradação da FDN do caroço de algodão integral e da torta de nabo forrageiro indica que a parede celular destes 
alimentos apresenta alta fermentação dos seus componentes solúveis. A superioridade da taxa de desaparecimento do caroço de algodão integral em relação à torta de nabo forrageiro se explica pela quantidade de hemicelulose presente no caroço de algodão integral $(21,45 \%)$ que foi cerca de 18 vezes maior em relação à torta de nabo $(1,20 \%)$.

O milho, por se tratar de um grão, é constituído basicamente de carboidratos não fibrosos. Neste tipo de alimento, os carboidratos estruturais estão presentes no tegumento da semente. Na Tabela 2 nota-se que, entre o tempo 0 e $3 \mathrm{~h}$, ocorreu uma grande elevação na degradação da FDA do milho, isto se deve ao fato de que grande parte da celulose que constitui esta fração fibrosa foi degradada durante as três primeiras horas de permanência no rúmen.

Os valores para a fração solúvel (A), fração insolúvel potencialmente degradável (B), fração não degradável (C), taxa de degradação por hora $(\mathrm{kd})$, degradabilidade potencial (DP), degradabilidade efetiva (DE) estimadas para as taxas de passagem da matéria seca de $3 ; 5$; e $8 \% / \mathrm{h}$, sugeridas pelo AFRC (1993) da matéria seca, matéria orgânica, proteína bruta, fibra em detergente neutro e fibra em detergente ácido podem ser observadas nas Tabelas $3,4,5,6$ e 7 .

Dentre os alimentos estudados, o caroço de algodão integral apresentou menores valores para a DP e para as DE a 3; 5 e 8\% (Tabela 3), o que pode ser devido ao elevado teor de casca e de línter presente neste alimento, associado ao elevado teor de óleo. Resultado semelhante foi verificado para a MO deste alimento (Tabela 4).

Os resultados verificados neste estudo foram semelhantes aos divulgados por Teixeira et al. (2002), ao estudar a cinética da digestão ruminal do caroço de algodão em diferentes formas físicas, que encontraram valores de $24,90 \%$ para a fração solúvel do caroço de algodão integral moído. O valor de $59,57 \%$ de DP (72 horas de incubação) observados neste estudo foi inferior aos divulgados por Beran et al. (2005) e Teixeira et al. (2002), 60,19\% (33 h de incubação) e 69,40\% (48 h de incubação), respectivamente. Esse menor valor verificado para a DP a um maior tempo de incubação, pode ser explicado pelo elevado teor de lignina presente no caroço de algodão integral utilizado neste trabalho $(8,40 \%)$.

Tabela 3. Valores das frações solúveis (A), insolúvel potencialmente degradável (B), indigestível (C), taxa de degradação (kd), degradabilidade potencial (DP), degradabilidade efetiva (DE) e tempo de colonização (Lag) da matéria seca (MS) dos alimentos incubados no rúmen.

\begin{tabular}{lcccccc}
\hline & \multicolumn{5}{c}{ Alimentos } & \multirow{2}{*}{ CV (\%) } \\
\cline { 2 - 5 } & CAI & FS & GG & TN & MT & \\
\hline A & $24,39^{\mathrm{c}}$ & $31,72^{\mathrm{b}}$ & $53,67^{\mathrm{a}}$ & $31,26^{\mathrm{b}}$ & $23,16^{\mathrm{c}}$ & 2,28 \\
$\mathrm{~B}$ & $36,01^{\mathrm{d}}$ & $66,60^{\mathrm{b}}$ & $19,43^{\mathrm{e}}$ & $57,90^{\mathrm{c}}$ & $75,99^{\mathrm{a}}$ & 3,93 \\
$\mathrm{C}$ & $39,57^{\mathrm{a}}$ & $1,67^{\mathrm{d}}$ & $26,89^{\mathrm{b}}$ & $10,83^{\mathrm{c}}$ & $0,85^{\mathrm{d}}$ & 16,76 \\
$\mathrm{kd}(\% / \mathrm{h})$ & $4,44 \mathrm{~b}^{\mathrm{cd}}$ & $5,74 \mathrm{a}^{\mathrm{b}}$ & $5,30^{\text {ad }}$ & $7,97^{\mathrm{a}}$ & $5,71 \mathrm{a}^{\mathrm{c}}$ & 25,58 \\
DP & $59,57^{\mathrm{c}}$ & $97,79^{\mathrm{a}}$ & $72,86^{\mathrm{b}}$ & $82,36^{\mathrm{b}}$ & $98,81^{\mathrm{a}}$ & 7,29 \\
DE3 & $45,43^{\mathrm{c}}$ & $74,81^{\mathrm{a}}$ & $65,76^{\mathrm{b}}$ & $73,08^{\mathrm{a}}$ & $72,88^{\mathrm{a}}$ & 3,61 \\
DE5 & $40,93^{\mathrm{b}}$ & $67,35^{\mathrm{a}}$ & $63,38^{\mathrm{a}}$ & $66,59^{\mathrm{a}}$ & $63,65^{\mathrm{a}}$ & 4,28 \\
DE8 & $36,93^{\mathrm{d}}$ & $57,45^{\mathrm{ac}}$ & $61,18^{\mathrm{a}}$ & $59,90^{\mathrm{ab}}$ & $54,79^{\mathrm{bc}}$ & 5,80 \\
Lag & $3,57^{\mathrm{c}}$ & $4,20^{\mathrm{ab}}$ & $2,86^{\mathrm{d}}$ & $4,01^{\mathrm{b}}$ & $4,29^{\mathrm{a}}$ & 3,44 \\
\hline
\end{tabular}

CAI - caroço de algodão integral, FS - farelo de soja, GG - grão de girassol, TN - torta de nabo forrageiro, MT - milho triturado.

a, b, c, d, e - Médias acompanhadas de letras diferentes na mesma linha diferem $(\mathrm{P}<0,05)$ pelo teste de Tukey.

DE3, DE5, DE8 - Degradabilidades efetivas com 3; 5 e 8\%/h como valores de taxa de passagem.

$\mathrm{CV}=$ coeficiente de variação. 
Tabela 4. Valores das frações solúveis (A), insolúvel potencialmente degradável (B), indigestível (C), taxa de degradação $(\mathrm{kd})$, degradabilidade potencial (DP), degradabilidade efetiva (DE) e tempo de colonização (Lag) da matéria orgânica $(\mathrm{MO})$ dos alimentos incubados no rúmen.

\begin{tabular}{lcccccc}
\hline & \multicolumn{5}{c}{ Alimentos } & \multicolumn{2}{c}{ CV (\%) } \\
\cline { 2 - 5 } \cline { 2 - 5 }$(\%)$ & CAI & FS & GG & TN & MT & \\
\hline A & $27,00^{\mathrm{d}}$ & $33,32^{\mathrm{b}}$ & $52,72^{\mathrm{a}}$ & $31,24^{\mathrm{c}}$ & $22,24^{\mathrm{e}}$ & 2,23 \\
$\mathrm{~B}$ & $32,37^{\mathrm{c}}$ & $61,56^{\mathrm{b}}$ & $19,68^{\mathrm{d}}$ & $58,47^{\mathrm{b}}$ & $73,94^{\mathrm{a}}$ & 4,46 \\
$\mathrm{C}$ & $40,62^{\mathrm{a}}$ & $5,11^{\mathrm{d}}$ & $27,59^{\mathrm{b}}$ & $3,97^{\mathrm{d}}$ & $10,89^{\mathrm{c}}$ & 12,96 \\
$\mathrm{kd}(\% / \mathrm{h})$ & $3,61^{\mathrm{c}}$ & $6,20^{\mathrm{b}}$ & $4,97 \mathrm{~b}^{\mathrm{c}}$ & $9,50^{\mathrm{a}}$ & $7,87 \mathrm{a}^{\mathrm{b}}$ & 20,86 \\
DP & $57,98^{\mathrm{d}}$ & $94,58^{\mathrm{a}}$ & $72,10^{\mathrm{c}}$ & $89,07^{\mathrm{b}}$ & $96,17^{\mathrm{a}}$ & 2,36 \\
DE3 & $38,58^{\mathrm{b}}$ & $60,14^{\mathrm{a}}$ & $59,84^{\mathrm{a}}$ & $55,94^{\mathrm{a}}$ & $56,41^{\mathrm{a}}$ & 16,68 \\
DE5 & $35,88^{\mathrm{b}}$ & $55,63^{\mathrm{a}}$ & $58,28^{\mathrm{a}}$ & $51,93^{\mathrm{a}}$ & $51,81^{\mathrm{a}}$ & 15,84 \\
DE8 & $33,60^{\mathrm{b}}$ & $51,13^{\mathrm{a}}$ & $56,91^{\mathrm{a}}$ & $47,88^{\mathrm{a}}$ & $46,84^{\mathrm{a}}$ & 14,47 \\
Lag & $3,28^{\mathrm{d}}$ & $4,01^{\mathrm{b}}$ & $2,88^{\mathrm{e}}$ & $3,69^{\mathrm{c}}$ & $4,46^{\mathrm{a}}$ & 2,20 \\
\hline
\end{tabular}

CAI - caroço de algodão integral, FS - farelo de soja, GG - grão de girassol, TN - torta de nabo forrageiro, MT - milho triturado.

a, b c c, d-Médias acompanhadas de letras diferentes na mesma linha diferem $(\mathrm{P}<0,05)$ pelo teste de Tukey.

DE3, DE5, DE8 - Degradabilidades efetivas com 3; 5 e $8 \% /$ h como valores de taxa de passagem.

$\mathrm{CV}=$ coeficiente de variação.

O caroço de algodão integral e o grão de girassol apresentaram as maiores frações indigestíveis, respectivamente 39,57 e $26,89 \%$, possivelmente devido às maiores quantidades de fibra presentes nestes alimentos. O farelo de soja e o milho triturado apresentaram as menores porcentagens para esta mesma fração, devido à alta solubilidade e as maiores porcentagens das frações potencialmente degradáveis encontradas para estes alimentos.

A fração solúvel da MS do farelo de soja encontrada neste estudo (31,72\%) foi inferior ao valor divulgado por Rossi Junior et al. (1997) (37,34\%). A fração solúvel, bem como a $\mathrm{DE}$ a 3 ; 5 e $8 \%$ foram semelhantes para o farelo de soja e a torta de nabo. Em relação à MO, a fração insolúvel potencialmente degradável, a fração indegradável e as $\mathrm{DE}$ a 3; 5 e 8\% também foram semelhantes para estes dois alimentos, levando a deduzir que a quantidade de energia disponível no rúmen, quando da utilização destes alimentos, será semelhante.

O grão de girassol, dentre os alimentos estudados, apresentou a maior fração solúvel da MS (53,67\%), resultado inferior aos relatados por Beran et al. (2005) e superior aos divulgados por Bett et al. (2004), 56,40\% e 32,40\%, respectivamente.
A DP da MO da torta de nabo forrageiro $(89,07 \%)$ foi superior a observada para o grão de girassol $(72,10 \%)$, o que leva a afirmar que o teor de óleo presente no grão de girassol prejudica a degradação e conseqüente disponibilização de nutrientes no interior do rúmen.

A fração insolúvel potencialmente degradável da MO do milho triturado (Tabela 4) foi superior à verificada por Silva (1999), que encontrou valor de $20,80 \%$ para esta fração. As DE a $3 ; 5$ e $8 \% / h$ da MO do milho e da torta de nabo forrageiro não apresentaram diferença entre si, indicando que a torta de nabo pode ser tão eficiente quanto o milho em fornecer energia para os microrganismos ruminais.

Os resultados encontrados neste estudo para as DE a $3 ; 5$ e $8 \% / h$ da PB do grão de girassol diferem daqueles encontrados por Beran et al. (2005), 92,59; 90,70; e 88,38\%, respectivamente, no entanto, assim como neste trabalho, os autores verificaram que este alimento apresentou as maiores $\mathrm{DE}$ em relação ao caroço de algodão integral e ao farelo de soja.

$\mathrm{O}$ caroço de algodão apresentou neste estudo, para a PB, fração solúvel, DP e DE a 5\%/h de 25,48; 
89,95 e $48,90 \%$ respectivamente. O valor encontrado neste estudo para a fração solúvel foi inferior aos divulgados por Teixeira et al. (2002) e Beran et al. (2005), 36,50 e 77,61\%, respectivamente.

Os alimentos analisados apresentaram teor de proteína não degradada no rúmen semelhante, com exceção do grão de girassol que apresentou menor teor de proteína by pass $(25,4 \%$ para $3 \% / \mathrm{h}$ de taxa de passagem), indicando que este alimento não é indicado para animais de alta produção que requerem maiores quantidades de proteína para ser digerida no intestino delgado.

O caroço de algodão integral apresentou fração solúvel da proteína bruta semelhante ao farelo de soja (Tabela 5), no entanto a fração indegradável do farelo de soja foi cerca de 26 vezes menor em relação à da $\mathrm{PB}$ do caroço de algodão, indicando que maior quantidade de nitrogênio estará disponível no interior do rúmen de animais que receberem farelo de soja.

A fração solúvel da PB do farelo de soja (24,37\%), foi superior aos valores divulgados na literatura, por Malafaia, Valadares Filho e Vieira (1997) (8,26\%); Martins et al. (1998) (22,30\%); Brisola et al. (1999) (11,80\%) e Cabral et al. (2000) (8,23\%). No entanto, Rossi Junior et al. (1997), Silva (1999), Silva et al. (2002), Souza et al. (2002), Beran et al. (2005) relataram valores superiores 40,$53 ; 25,30 ; 56,99$; 35,40 e $28,30 \%$, respectivamente.

Tabela 5. Valores das frações solúveis (A), insolúvel potencialmente degradável (B), indigestível (C), taxa de degradação (kd), degradabilidade potencial (DP), degradabilidade efetiva (DE) e tempo de colonização (Lag) da proteína bruta $(\mathrm{PB})$ dos alimentos incubados no rúmen.

\begin{tabular}{lcccccc}
\hline & \multicolumn{5}{c}{ Alimentos } & CV (\%) \\
\cline { 2 - 5 } & CAI & FS & GG & TN & MT & \\
\hline A & $25,48^{\mathrm{d}}$ & $24,37^{\mathrm{d}}$ & $62,36^{\mathrm{a}}$ & $34,18^{\mathrm{b}}$ & $28,24^{\mathrm{c}}$ & 3,93 \\
$\mathrm{~B}$ & $64,54^{\mathrm{ab}}$ & $75,23^{\mathrm{a}}$ & $29,18^{\mathrm{c}}$ & $61,92^{\mathrm{b}}$ & $60,52^{\mathrm{b}}$ & 12,42 \\
$\mathrm{C}$ & $9,97^{\mathrm{a}}$ & $0,38^{\mathrm{d}}$ & $8,45^{\mathrm{b}}$ & $3,89^{\mathrm{c}}$ & $2,85^{\mathrm{c}}$ & 13,62 \\
$\mathrm{kd}(\% / \mathrm{h})$ & $7,20^{\mathrm{a}}$ & $8,21^{\mathrm{a}}$ & $6,61^{\mathrm{a}}$ & $8,75^{\mathrm{a}}$ & $8,17^{\mathrm{a}}$ & 19,05 \\
DP & $89,95^{\mathrm{d}}$ & $99,55^{\mathrm{a}}$ & $91,45^{\mathrm{c}}$ & $96,06^{\mathrm{b}}$ & $97,09^{\mathrm{b}}$ & 0,59 \\
DE3 & $53,71^{\mathrm{b}}$ & $58,23^{\mathrm{b}}$ & $74,60^{\mathrm{a}}$ & $61,85^{\mathrm{ab}}$ & $58,83^{\mathrm{b}}$ & 11,76 \\
DE5 & $48,95^{\mathrm{b}}$ & $53,20^{\mathrm{b}}$ & $72,50^{\mathrm{a}}$ & $57,82^{\mathrm{b}}$ & $54,18^{\mathrm{b}}$ & 11,26 \\
DE8 & $44,34^{\mathrm{b}}$ & $48,05^{\mathrm{b}}$ & $70,42^{\mathrm{a}}$ & $53,58^{\mathrm{b}}$ & $49,37^{\mathrm{b}}$ & 10,49 \\
Lag & $4,05^{\mathrm{b}}$ & $4,07^{\mathrm{b}}$ & $3,29^{\mathrm{c}}$ & $4,04^{\mathrm{b}}$ & $4,36^{\mathrm{a}}$ & 2,24 \\
\hline
\end{tabular}

$\mathrm{CAI}$ - caroço de algodão integral, FS - farelo de soja, GG - grão de girassol, TN - torta de nabo forrageiro, MT - milho triturado. a, b, c, d-Médias acompanhadas de letras diferentes na mesma linha diferem $(\mathrm{P}<0,05)$ pelo teste de Tukey.

DE3, DE5, DE8 - Degradabilidades efetivas com 3; 5 e 8\%/h como valores de taxa de passagem.

$\mathrm{CV}=$ coeficiente de variação.

A fração não degradável da PB do farelo de soja encontrada, neste estudo, foi superior aos $0,18 \%$ relatados por Rossi Junior et al. (1997) e Brisola et al. (1999), e inferior aos 1,$38 ; 0,55 ; 0,98 ; 2,70 \%$ divulgados por Malafaia, Valadares Filho e Vieira (1997), Rossi Junior et al. (1997), Cabral et al. (2000) e Souza et al. (2002), respectivamente.

Os $99,55 \%$ de DP da PB do farelo de soja foram semelhantes aos divulgados por Beran et al. (2005)
(99,52\%) e superiores aos relatados por Rossi Junior et al. (1997), de 98,82\% para dietas com $82 \%$ de volumoso e $96,93 \%$ para dietas com $61 \%$ de volumoso.

A DE da PB do farelo de soja observada neste trabalho a $3 \% / \mathrm{h}$ de taxa de passagem foi $58,23 \%$, valor inferior ao relatado por Rossi Junior et al. (1997) de 86,06\%, com taxa de passagem de $3,74 \% / h$. A DE da PB do farelo de soja, para taxa 
de passagem de $5 \% / \mathrm{h}$ foi de $53,20 \%$, valor inferior aos 85,22 e $86,56 \%$ relatados por Silva et al. (2002) e Beran et al. (2005).

A torta de nabo forrageiro apresentou baixa DP da FDN e da FDA (Tabela 6 e 7), conseqüência de uma elevada fração indigestível presente neste alimento. O caroço de algodão integral, também, apresenta elevada fração indigestível. No entanto, as DE deste alimento, são maiores em relação à torta de nabo forrageiro em decorrência da maior taxa de degradação da fração potencialmente degradável no rúmen, presente no caroço de algodão integral.
Os valores encontrados para a DP da FDN do farelo de soja e do milho triturado (Tabela 6 e 7) foram superiores aquelas relatadas por Silva (1999), 82,6 e $40,40 \%$ respectivamente.

O farelo de soja apresentou valores para as DE a 3; 5 e $8 \% /$ h da FDA superiores aos demais alimentos, conseqüência de uma elevada fração solúvel e baixa fração indigestível (Tabela 7). Os valores observados neste estudo foram superiores aos relatados por Silva (1999) para a fração solúvel $(27,60 \%)$ e DE a 5 e $8 \% /$ h da FDA, 66,50; 58,90\%, respectivamente.

Tabela 6. Valores das frações solúveis (A), insolúvel potencialmente degradável (B), indigestível (C), taxa de degradação (kd), degradabilidade potencial (DP), degradabilidade efetiva (DE) e tempo de colonização (Lag) da fibra em detergente neutro (FDN) dos alimentos incubados no rúmen.

\begin{tabular}{lcccccc}
\hline & \multicolumn{5}{c}{ Alimentos } & \multicolumn{2}{c}{ CV (\%) } \\
\cline { 2 - 5 } & CAI & FS & GG & TN & MT & \\
\hline A & $16,12^{\mathrm{b}}$ & $16,06^{\mathrm{b}}$ & $23,24^{\mathrm{a}}$ & $6,74^{\mathrm{c}}$ & $8,04^{\mathrm{c}}$ & 4,23 \\
B & $45,02^{\mathrm{c}}$ & $51,08^{\mathrm{b}}$ & $54,76^{\mathrm{a}}$ & $34,15^{\mathrm{e}}$ & $42,00^{\mathrm{d}}$ & 2,99 \\
C & $38,84^{\mathrm{c}}$ & $38,85^{\mathrm{c}}$ & $21,98^{\mathrm{d}}$ & $59,10^{\mathrm{a}}$ & $49,95^{\mathrm{b}}$ & 4,79 \\
Kd & $2,16^{\mathrm{c}}$ & $7,37^{\mathrm{a}}$ & $4,90^{\mathrm{b}}$ & $2,02^{\mathrm{c}}$ & $5,40^{\mathrm{b}}$ & 12,93 \\
DP & $55,42^{\mathrm{c}}$ & $83,89^{\mathrm{a}}$ & $77,44^{\mathrm{b}}$ & $35,95^{\mathrm{e}}$ & $49,70^{\mathrm{d}}$ & 3,00 \\
DE3 & $34,97^{\mathrm{c}}$ & $69,15^{\mathrm{a}}$ & $57,09^{\mathrm{b}}$ & $20,50^{\mathrm{d}}$ & $34,85^{\mathrm{c}}$ & 4,34 \\
DE5 & $29,72^{\mathrm{b}}$ & $57,90^{\mathrm{a}}$ & $50,24^{\mathrm{a}}$ & $16,59^{\mathrm{c}}$ & $29,69^{\mathrm{b}}$ & 14,09 \\
DE8 & $25,71^{\mathrm{c}}$ & $53,02^{\mathrm{a}}$ & $43,96^{\mathrm{b}}$ & $13,65^{\mathrm{d}}$ & $24,85^{\mathrm{c}}$ & 13,42 \\
Lag & $3,45^{\mathrm{b}}$ & $3,99^{\mathrm{a}}$ & $3,85^{\mathrm{a}}$ & $3,15^{\mathrm{c}}$ & $3,90^{\mathrm{a}}$ & 3,64 \\
\hline
\end{tabular}

CAI - caroço de algodão integral, FS - farelo de soja, GG - grão de girassol, TN - torta de nabo forrageiro, MT - milho triturado. $\mathrm{a}, \mathrm{b}, \mathrm{c}, \mathrm{d}$ - Médias acompanhadas de letras diferentes na mesma linha diferem $(\mathrm{P}<0,05)$ pelo teste de Tukey.

DE3, DE5, DE8 - Degradabilidades efetivas com 3; 5 e 8\%/h como valores de taxa de passagem.

$\mathrm{CV}=$ coeficiente de variação.

Tabela 7. Valores das frações solúveis (A), insolúvel potencialmente degradável (B), indigestível (C), taxa de degradação (kd), degradabilidade potencial (DP), degradabilidade efetiva (DE) e tempo de colonização (Lag) da fibra em detergente ácido (FDA) dos alimentos incubados no rúmen.

\begin{tabular}{lcccccc}
\hline & \multicolumn{5}{c}{ Alimentos } & \multicolumn{2}{c}{ CV (\%) } \\
\cline { 2 - 5 } & CAI & FS & GG & TN & MT & \\
\hline A & $9,91^{\mathrm{c}}$ & $26,10^{\mathrm{a}}$ & $13,98^{\mathrm{b}}$ & $7,02^{\mathrm{d}}$ & $6,38^{\mathrm{d}}$ & 5,03 \\
B & $47,14^{\mathrm{d}}$ & $70,52^{\mathrm{b}}$ & $62,05^{\mathrm{c}}$ & $56,19^{\mathrm{a}}$ & $29,83^{\mathrm{e}}$ & 1,76 \\
C & $42,95^{\mathrm{b}}$ & $3,38^{\mathrm{e}}$ & $23,94^{\mathrm{c}}$ & $63,15^{\mathrm{a}}$ & $6,79^{\mathrm{d}}$ & 3,70 \\
Kd & $3,072^{\mathrm{c}}$ & $6,24^{\mathrm{a}}$ & $4,80^{\mathrm{b}}$ & $1,14^{\mathrm{b}}$ & $6,78^{\mathrm{a}}$ & 8,12 \\
DP & $54,53^{\mathrm{d}}$ & $96,44^{\mathrm{a}}$ & $75,41^{\mathrm{c}}$ & $36,20^{\mathrm{e}}$ & $92,93^{\mathrm{b}}$ & 1,14 \\
DE3 & $33,72^{\mathrm{d}}$ & $73,72^{\mathrm{a}}$ & $52,13^{\mathrm{c}}$ & $24,24^{\mathrm{e}}$ & $64,87^{\mathrm{b}}$ & 2,37 \\
DE5 & $27,81^{\mathrm{d}}$ & $65,25^{\mathrm{a}}$ & $44,38^{\mathrm{c}}$ & $20,48^{\mathrm{e}}$ & $54,50^{\mathrm{b}}$ & 2,86 \\
DE8 & $22,96^{\mathrm{d}}$ & $57,01^{\mathrm{a}}$ & $37,22^{\mathrm{c}}$ & $44,45^{\mathrm{b}}$ & $17,16^{\mathrm{e}}$ & 3,21 \\
Lag & $3,69^{\mathrm{d}}$ & $4,32^{\mathrm{a}}$ & $4,04^{\mathrm{b}}$ & $3,22^{\mathrm{e}}$ & $3,84^{\mathrm{c}}$ & 0,68 \\
\hline
\end{tabular}

CAI - caroço de algodão integral, FS - farelo de soja, GG - grão de girassol, TN - torta de nabo forrageiro, MT - milho triturado. a, b, c, d, e - Médias acompanhadas de letras diferentes na mesma linha diferem $(\mathrm{P}<0,05)$ pelo teste de Tukey.

DE3, DE5, DE8 - Degradabilidades efetivas com 3; 5 e 8\%/h como valores de taxa de passagem.

$\mathrm{CV}=$ coeficiente de variação. 
O caroço de algodão integral, também, apresentou elevada fração indigestível. No entanto, as $\mathrm{DE}$ deste alimento, são maiores em relação à torta de nabo forrageiro em decorrência da maior taxa de degradação da fração potencialmente degradável no rúmen, presente no caroço de algodão integral.

A torta de nabo forrageiro é um alimento que apresenta características que possibilitam sua utilização na alimentação de ruminantes. A semelhança no comportamento da degradação da proteína bruta entre este co-produto e o farelo de soja, indica a possibilidade de substituição do farelo de soja pela torta de nabo forrageiro.

Adegradação da matéria orgânica da torta de nabo forrageiro permite inferir que a utilização deste coproduto, como fonte energética, apresenta resultados semelhantes em relação ao milho triturado, com vantagens em relação ao teor de proteína bruta.

Em virtude da alta quantidade de proteína solúvel presente no grão de girassol, o fornecimento de grãos inteiros pode ser interessante, principalmente com o objetivo de promover uma degradação mais lenta deste componente nutritivo no interior do rúmen e promover maior disponibilidade de proteína verdadeira nos intestinos.

O caroço de algodão integral, em virtude do seu elevado teor de óleo, quando fornecido triturado, pode trazer problemas relacionados ao decréscimo na degradação da fração fibrosa da dieta e alterações no metabolismo ruminal. Isto ocorre porque a quebra do caroço proporciona maior disponibilidade de óleo no interior do rúmen que forma uma camada sobre a fibra dificultando o ataque microbiano.

\section{Conclusões}

A torta de nabo forrageiro apresenta potencial para substituir o farelo de soja como fonte protéica na alimentação de ruminantes.

O grão de girassol apresenta alta solubilidade da PB, necessitando maior cuidado na utilização deste alimento como fonte protéica, principalmente em animais de alta produção.

O teor de extrato etéreo presente no caroço de algodão integral afetou negativamente a degradação da matéria seca e da matéria orgânica deste alimento.

\section{Agradecimentos}

À Empresa Biolix, na pessoa do Sr. Félix, por fornecer a torta de nabo forrageiro, alimento concentrado utilizado neste estudo.

\section{Referências}

AGRICULTURALAND FOOD RESEARCH COUNCIL - AFRC. Energy and protein requirements of ruminants. Walligford: CAB International, 1993.

AROEIRA, L. J. M.; LOPES, F. C. F.; DAYRELL, M. S. Degradabilidade de alguns alimentos no rúmen de vacas holandês/zebu. Revista Brasileira de Zootecnia, Viçosa, v. 25, n. 6, p. 1179-1186, 1996.

BERAN, F. H. B.; SILVA, L. D. F.; RIBEIRO, E. L. A.; CASTRO, V. S.; CORREA, R. A.; KAGUEYAMA, E. O.; ROCHA, M. A. Degradabilidade ruminal in situ da matéria seca e proteína bruta de alguns suplementos concentrados usados na alimentação de bovinos. Semina: Ciências Biológicas e da Saúde, Londrina, v. 26, n. 3, p. 405-418, 2005.

BETT, V.; OLIVEIRA, M. D. S.; SOARES, W. V. B.; IZIQUIEL, J. M. B. Digestibilidade in vitro e degradabilidade in situ de diferentes variedades de grãos de girasssol (Helianthus annuus L.). Acta Scientiarum: Animal Sciences, Maringá, v. 26, n. 4, p. 513-519, 2004.

BRISOLA, M. L.; LUCCI, C. S.; MELOTTI, L.; KODAIRA,V. Degradabilidade ruminal in situ da matéria seca e proteína bruta do farelo e dos grãos de soja extrusados. Brazilian Journal of Reserch Animal Science, São Paulo, v. 36, n. 3, p. 1999. Disponível em: $\quad<$ http://www.scielo.br/scielo.php?script=sci arttext\&pid=S1413-95961999000300009\&lng=pt\&nrm $=$ iso\&tlng $=\mathrm{pt}>$. Acesso em: $26 \mathrm{dez} .2007$.

CABRAL, L. S.; VALADARES FILHO, S. C.; MALAFAIA, P. A. M.; VIEIRA, R. A. M. Frações protéicas de alimentos tropicais e suas taxas de digestão estimadas pela incubação com proteases ruminais. 
Revista Brasileira de Zootecnia, Viçosa, v. 29, n. 26, p. 2316-2324, 2000.

GABARRA, P. R. Digestibilidade de nutrientes $e$ parâmetros ruminais e sangüineos de novilhos nelore alimentados com fontes protéicas e energéticas com diferentes degradabilidades ruminais. 2001. Dissertação (Mestrado em Agronomia) - Universidade de São Paulo, Escola Superior de Agricultura Luiz de Queiroz, Piracicaba.

HOOVER, C.W.; STOKES, S. R. Balacing carbohydrates and proteins for optimum rúmen microbial yield. Journal of Dairy Science, Champaign, v. 74, n. 11, p. 3630-3640, 1991.

JOHNSON, R. R. Thechniques and procedures for in vitro and in vivo rumen studies. Journal Animal Science, Champaign, v. 25, n. 3, p. 855-875, 1966.

LANNA, D. P. D.; TEDESCHI, L. O.; BELTRAME FILHO, L. A. Modelos lineares e não lineares de uso de nutrientes para a formulação de dietas de ruminantes. Scientia Agricola, São Paulo, v. 56, n. 2, p. 479-488, 1999.

MALAFAIA, P. A. M.; VALADARES FILHO, S. C. ; VIEIRA R. A. M. Determinação e cinética ruminal das frações protéicas de alguns alimentos para ruminantes. Revista Brasileira de Zootecnia, Viçosa, v. 26, n. 6, p. 1243-1251, 1997.

MARTINS, A. S.; ZEOULA, L. M.; PRADO, I. N.; MICHELAN, A. C.; SANTOS, G. T. Degradação ruminal da matéria seca e da proteína bruta de alguns alimentos. In: REUNIÃO ANUAL DA SOCIEDADE BRASILEIRA DE ZOOTECNIA, 35., 1998, Botucatu. Anais... Botucatu: SBZ, 1998. p. 323 -325.

MEHREZ, A. Z.; ORSKOV, E. R. A study of the artificial fibre bag technique for determining the digestibility of feeds in the rumen. Journal of Agriculture Science, Cambridge v. 88, n. 3, p. 645-650, 1977.

MIR, Z.; MAcLEOD, G. K.; BUCHANAN-SMITH, J. G.; GRIEVE, D. G.; GROVUM, W. L. Methods for protecting soybean and canola proteins from degradation in the rumen. Canadian Journal of Animal Science, Ottawa, v. 64, n. 4, p. 853-865, 1984.

MOREIRA, J. F. C.; RODRIGUÉZ, N. M.; FERNANDES, P. C. C.; VELOSO,C. M.; SALIBA,E. O. S.; GONÇALVES, L. C.; BORGES, I.; BORGES, A. L. C. C. Concentrados protéicos para bovinos. 1. digestibilidade in situ da matéria seca e da proteína bruta. Arquivo Brasileiro de Medicina Veterinária e Zootecnia, Belo Horizonte, v. 55, n. 3, p. 324-333, 2003.
NATIONAL RESEARCH COUNCIL - NRC. Nutrient requirements of dairy cattle. 7. ed. Washington: National Academy Press, 1996.

NEUMANN, M.; RESTLE, J.; ALVES FILHO, D. C.; BRONDANI, I. L.; MENEZES, L. F. G. Resposta econômica da terminação de novilhos em confinamento, alimentados com silagens de diferentes híbridos de sorgo. Ciência Rural, Santa Maria, v. 32, n. 5, p. 849854, 2002.

NOCEK, J. E.; RUSSEL, J. B. Protein and energy as an integrated system: Relationship of ruminal protein and carbohydrate availability to microbial synthesis and milk production. Journal of Dairy Science, Champaing, v. 71, n. 8, p. 2070-2082, 1988.

NORLAN, J. V. Quantitative models of nitrogen metabolism in sheep. In: MACDONALD, I. W.; WARNER, A. C. I. (Ed.). Digestion and metabolism in the ruminant. Armidale: University New England, 1975. p. 398-416.

ORSKOV, E. R.; MCDONALD, I. The estimation of protein degradability in the rumen fron incubation measurements weighted according to rate of passage. Journal of Agriculture Science, Cambridge, v. 92, n. 2, p. 499-503, 1979.

ORSKOV, E. R.; HOVELL, F. D. D.; MOULD, F. The use of the nylon technique for the evaluation of feedstuffs. Tropical Animal Production, Santo Domingo, v. 5, n. 3, p. 195-213, 1980.

PALMQUIST, D. L.; JENKINS, T. C. Fat in lactation rations: review. Journal of Dairy Science, Champaing, v. 63, n. 10, p. 1-14, 1980.

PENIDO, H. R. Biodísel: debates e propostas. A inclusão social, a preservação ambiental e os ganhos econômicos. Disponível em: <ttp://jus2.uol.com.br/doutrina/texto>. Acesso em: $31 \mathrm{dez} .2007$.

PRESTON, R. L. Management of high concentrate diets in feedlot. In: SIMPÓSIO SOBRE PRODUÇÃO INTENSIVADE GADO DE CORTE, 1., 1998, Campinas. Anais... Campinas: CBNA, 1998. p. 82-91.

ROSSI JUNIOR, P.; SILVA, A. G.; WANDERLEY, R. C.; BOSE, M. L. V.; BOIN, C. Degradabilidade ruminal da matéria seca e da fração protéica da silagem de milho, do farelo de soja e sorgo grão, em bovinos da raça nelore. Comparação com os dados obtidos pelo CNCPS. Revista Brasileira de Zootecnia, Viçosa, v. 26, n. 4, p. 599-607, 1997.

SILVA, J. F. C.; LEÃO, M. I. Fundamentos de nutrição de ruminantes. São Paulo: Livroceres, 1979. 
SILVA, L. D. F. Degradabilidade ruminal da casca de soja e fontes protéicas e seus efeitos nas digestões ruminal e intestinal de bovinos. 1999. Tese. (Doutorado em Zootecnia) - Universidade Estadual Paulista, Faculdade de Ciências Agrárias e Veterinárias de Jaboticabal, Jaboticabal.

SILVA, L. D. F.; RAMOS, B. M. O.; RIBEIRO, E. L. A.; MIZUBUTI, I. Y.; ROCHA, M. A.; MORAES, F. L. Z. Degradabilidade ruminal in situ da matéria seca e proteína bruta de duas variedades de grão de soja com diferentes teores de inibidor de tirpsina em bovinos. Revista Brasileira de Zootecnia, Viçosa, v. 31, n. 3, p. 1251-1257, 2002.

SMITH, M. E.; COLLAR, L. S.; BATH, D. L.; DUNKLEY, W. L.; FRANKE, A. A. Digestibility and effects of whole cottonseed fed to lactating cows. Journal of Dairy Science, Champaing, v. 64, n. 11, p. 2209-2215, 1981.

SNIFFEN, C. J.; O'CONOR, J. D.; FOX, D. G.; FOX, D. G.; RUSSELL, J. B. A net carbohydrate and protein system for evaluating cattle diets. II. Carbohydrate and protein availability. Journal Animal Science, Champaign, v. 70, n. 12 , p. 3562-3577, 1992.

SOUZA, M. S.; EZEQUIEL, J. M. B.; ROSSI JÚNIOR, P.; MALHEIROS, E. B. Efeitos de fontes nitrogenadas com distintas degradabilidades sobre o aproveitamento da fibra, do nitrogênio e do amido em rações para bovinos. Revista Brasileira de Zootecnia, Viçosa, v. 31, n. 5, p. 2139-2148, 2002.
STATISTICAL ANALYSIS SYSTEM - SAS. User's guide. Cary: SAS Institute, 2003.

TEIXEIRA, J. C.; SILVA, E. A.; BRAGA, R. A. N.; MORON, I. R. Cinética da digestão ruminal do caroço de algodão e do grão de milho em diferentes formas físicas em vacas holandesas. Ciência e Agrotecnologia, Lavras, v. 26, n. 4, p. 842-845, 2002.

VAN SOEST, P. J. Nutricional ecology of the ruminant. Ithaca: Cornell University Press, 1994.

VILLELA, S. D. J.; VALADARES FILHO, S. C; SILVA, F. F. C.; LEÃO, M. I.; CECON, P. R.; PEREIRA, J. C. Caroço de algodão para vacas leiteiras. I. Consumo de nutrientes, produção e composição do leite. Revista Brasileira de Zootecnia, Viçosa, v. 25, n. 2, p. 298-308, 1996.

ZEOULA, L. M.; CALDAS NETO, S. F. Recentes avanços em amido na nutrição de vacas leiteiras. In: SIMPÓSIO INTERNACIONAL EM BOVINOCULTURA DE LEITE: NOVOS CONCEITOS EM NUTRIÇÃO, 2., 2001, Lavras. Anais... Lavras: Ed. da UFLA, 2001. p. 199-228.

ZINN, R. A.; SHEN, Y. An evaluation of ruminal degradable intake protein and metabolizable amino acid requirements of feedlot calves. Journal of Animal Science, Champaing, v. 76, n. 5, p. 1280-1289, 1998. 
